\title{
Learning through public involvement in environmental assessment hearings
}

\author{
Patricia Fitzpatrick $^{\mathrm{a}, *}$, A. John Sinclair ${ }^{\mathrm{b}}$ \\ ${ }^{a}$ Department of Geography, University of Waterloo, Waterloo, Ont., Canada N2L 3G1 \\ ${ }^{\mathrm{b}}$ Natural Resources Institute, University of Manitoba, Winnipeg, Man., Canada R3T 2N2
}

Received 26 November 2001; revised 8 August 2002; accepted 9 September 2002

\begin{abstract}
This research examined the opportunities for critical education available to participants of a federal environmental assessment (EA) that includes hearings. The Sable Gas Panel Review, an assessment of a natural gas project situated in the Maritimes, was undertaken between 1996 and 1997. This study documented what participants learned through their experiences and how that learning was facilitated. Primary data collection emphasized the use of semi-structured interviews to record the experientially based observations of panel participants. Primary data were supported by a review of material submitted by hearing participants for consideration by the panel, and complemented with literature related to EA, environmental education, and transformational learning theories. Evidence was considered in terms of assessment-specific operational definitions, developed from Shor (1993) [Education is politics: Paulo Freire's Critical Pedagogy. In: McLaren, P., Leonard, P. (Eds.), Paulo Freire : A critical Encounter, Routledge, New York, pp. 25-35] ten indicators of critical education. The study revealed that participants of the Sable Gas panel review had an opportunity to engage in critical education. While it is important to acknowledge that the panel did not set out to engage participants in a 'critical educational' experience, each of the 10 operational definitions of critical education used in the study were addressed to varying degrees through activities undertaken by the panel secretariat. Results illustrate the types of educational opportunities, such as a class on how to participate in a quasi-judicial hearing, and the importance of participant-led research that can arise out of the panel review process. The findings of this research contribute to the evolving literature regarding the role of critical education in EA and environmental management. Understanding the existing scope of critical education within a panel review provides the foundation for identifying opportunities for expanding the capacity of the existing EA process to facilitate learning by participants.
\end{abstract}

(C) 2002 Elsevier Science Ltd. All rights reserved.

Keywords: Critical education; Individual learning; Public participation

\section{Introduction}

Environmental assessment (EA) is a proactive planning tool that allows developers, regulatory authorities, scientists, and the public to identify, evaluate, and mitigate, where possible, the potential changes to an environment from a proposed initiative before development is undertaken. The systematic consideration of economic, ecological and human impacts of development initiatives serves as the impetus for the inclusion of public involvement in EA. Providing members of the public an opportunity to participate in the assessment process enriches outcomes

\footnotetext{
* Corresponding author. Tel.: +1-519-888-4567x5492; fax: +1-519746-0658.

E-mail addresses: fitzpatrickpj@hotmail.com (P. Fitzpatrick), jsincla@ ms.umanitoba.ca (A.J. Sinclair).
}

of the process through incorporating varied knowledge and opinions with the information base.

All assessment legislation in Canada, both at provincial and federal levels, includes some provision for the incorporation of public comments. The need for public participation in EA decision making is well established both in theoretical and applied assessment literature (Parenteau, 1988; Webler, 1995). In addition to contributing to the general goal of individual empowerment, public participation:

- accentuates the effectiveness of the EA process (Mitchell, 1997);

- actualizes the principles of democracy (Gelhorn, 1971; Fox, 1979; Zimmerman, 1986; Shepard and Bowler, 1997); 
- ensures that the project meets the needs of the public, in terms of both purpose and design (Pearce et al., 1979; Forester, 1989; Tauxe, 1995; Shepard and Bowler, 1997);

- assigns legitimacy to a project because the assessment process appears to be transparent (Chapin and Deneau, 1978; Susskind and Cruikshank, 1987);

- provides avenues for conflict resolution for stakeholders (Mitchell, 1997; Shepard and Bowler, 1997; Diduck, 1999);

- provides a forum for the submission and inclusion of local knowledge in the EA decision (Usher, 2000); and

- provides for a more comprehensive consideration of factors on which decisions are based (Parenteau, 1988; Webler et al., 1995; Shepard and Bowler, 1997).

Education is important to public involvement. In terms of EA, education creates 'an awareness of the process and facilitates an understanding of substantive environmental, economic and social issues' (Diduck and Sinclair, 1997a: 295-296). This awareness centres on providing members of the public a foundation for effective participation in consultation initiatives by ensuring the public knows how to participate in an EA, and that participants have a basic comprehension of the complex issues related to the specific project under review. As such, education becomes both a precondition for, and an outcome of, fair and effective consultation of stakeholders. Furthermore, according to Webler et al. (1995), "if public participation practitioners orient processes to promote social learning then public participation will become more effective at strengthening democracy and overcoming the tendency of people to be rational egotists."

When exploring opportunities to facilitate learning by participants in environmental-based programming, it is important to consider educational theory. In this regard, promoters of environmental education support the utilization of transformational theory (Sinclair and Diduck, 1995; Diduck and Sinclair, 1997a,b; Alexander, 1999; Diduck, 1999; Palerm, 2000). Grounded in the ideologies of critical pedagogy (Freire, 1973), transformational learning theories focus on cognitive processes of learning, and how students construct meaning from experiences (Merriam and Caffarella, 1999). Learning is a vehicle for change, 'dramatic, fundamental change in the way we see ourselves and the world in which we live' (Merriam and Caffarella, 1999: 318). Discourse surrounding transformational theory centers on how to encourage learning so an individual's perceptions and consciousness can be altered as that person is critically engaged (Merriam and Caffarella, 1999). Education is the process through which the socialization of existing power relationships is perpetuated or transformed. It is 'one place where the individual and society are constructed; a social action which can either empower or domesticate students' (Shor, 1993: 25). With an emphasis on behaviour and social change, transformational theory is regarded as a vehicle through which a sustainable society can be promoted and secured (Usang, 1992; Orr, 1994; Clover, 1995, 1996; Sinclair and Diduck, 1995; Diduck and Sinclair, 1997a,b; Diduck, 2001; Fitzpatrick, 2001).

The purpose of this research was to explore the opportunities for critical education through EA. An examination of the opportunities for public participation in the Sable Gas Panel Review documented what participants learned through their experiences, how that learning was facilitated, and the importance of such learning to EA public involvement programs. It also provided data through which the opportunities for critical education were identified, evaluated, and related to shortcomings in public participation programs.

\section{Theoretical framework}

Critical education is a theory of teaching grounded in the philosophy of critical pedagogy. Critical pedagogy encourages a form of education in which the teacher and students are critical co-investigators in learning. Through a process of action, critical reflection, and action, called praxis, a learner can work to overcome the political power relationships manifest in traditional teaching techniques. Education becomes a venue for emancipation or empowerment of both the student and educator when the praxis of identities, theories, and teaching methods are encouraged. 'This pedagogy makes oppression and its causes objects of reflection by the oppressed, and from that reflection comes the necessary engagement in the struggle for their liberation' (Freire, 1973: 33). Critical pedagogy encourages-even requires-conscious consideration of traditional power structures implicit in the content and mechanisms of traditional educational systems.

Critical education is the manifestation of critical pedagogy in terms of opportunities for formal and non-formal education. Shor (1993) provides guidance on how to implement critical pedagogy in the form of ten descriptors (Table 1). These descriptors espouse the principles behind critical pedagogy, and detail conditions through which an individual's consciousness may develop. Methods promoting critical education reflect these conditions, and arise from an interactive and co-operative educational forum (Shor, 1993: 33).

Shor's descriptors of critical pedagogy provided the basis for the criteria with which the Sable Gas Panel Review was assessed. Operational definitions for the criteria were developed by applying the concepts established in critical education literature to EA public involvement processes, as identified in Table 1. Once developed, the criteria were reviewed by academics and EA practitioners and modified accordingly. 
Table 1

Conditions through which critical education can develop as part of the panel process, and associated conceptual and operational definitions. Criteria highlighted in bold print are discussed in the body of this text

Criteria and conceptual definition Operational definition

Participatory

Learners have a voice in education

Situated

Material reflects learners' thoughts and language

Democratic

Educators and learners work together to develop the learning agenda

Dialogic

Learning methods emphasize discussion

Desocialization

Education encourage active participation in education

Multicultural

Curriculum acknowledges cultural diversity

Research-oriented

The teacher studies the identity of student; and students research problems posed in class

Activist

The classroom is both active and interactive

Critical

The dialogue promotes self-reflection and social analysis

Affective

Discussion interested in broad feelings
Did the learners participate in developing the scope of the environmental assessment?

Were the participants encouraged to participate in the conformity analysis? Was the EA documentation presented in plain language?

Were the hearings conducted in a way encourage participation? Were steps taken to modify the hearings process to level power relations?

Was all material presented given equal consideration (as opposed to discounted beause of process or methodology)?

Were participants encouraged to dialogue outside the formal process?

Did the process encourage dialogue about potential solutions to outstanding issues?

Were steps taken to encourage inactive publics to participate?

Was he hearings open to all people who wanted to participate?

Was the public able to become part of the panel's EA decision?

Were efforts made to engage people from diverse cultural backgrounds in the hearings?

Did the process reflect the needs of participants (translation, location, process, etc.)?

Did the panel encourage independent research by participants?

Did the panel investigate he participants and tailor the materials to reflect their needs?

Did the panel investigate the participants and tailor the materials to reflect their needs?

Did the material presented during the panel contribute to future research initiatives?

Did the hearings process encourage participants to engage in experiential learning?

Were participants given an opportunity to critically reflect on the written documentation before the commencement of the hearings?

Was there aaaan opportunity for participants to critically reflect on the material presented during the hearings before being required to respond? What relationships developed among participants as the result of participation in the process

\section{Data collection and analysis}

The primary data for this research were collected through a case study approach including document reviews and semi-structured qualitative interviews. The proposal to exploit natural gas off the shore of Sable Island provided the case study. The initiative was a joint venture between Mobile Oil Canada, Shell Canada Limited, Imperial Oil Resources Limited, and Nova Scotia Resources Limited. The project, that triggered an EA including panel hearings in 1996, called for extraction of natural gas from six offshore reserves, and its transportation to a processing plant, to be built near Goldboro, Nova Scotia. The offshore component included 'gas wells, platforms and sub-sea gathering pipelines, a main sub-sea pipeline for transporting gas and liquids to the mainland at Isaacs Harbour, a gas processing plant near Goldboro, and a subsurface natural gas liquids pipeline from the gas plant to a handling and shipping facility at Point Tupper' (Sears, 1997: 1).
Gas would then be transported to markets in the United States through a pipeline constructed through Nova Scotia and New Brunswick by Maritimes and Northeast Pipeline Company.

The proposal was subject to numerous regulatory regimes, and as such, triggered reviews under five different jurisdictions: the National Energy Board; the Nova ScotiaCanada Offshore Petroleum Board; the Province of Nova Scotia (the Nova Scotia Environment Act); the Province of New Brunswick; and the Canadian Environmental Assessment Act. The Agreement for a Joint Public Review of the Proposed Sable Gas Panel Reviews (hereafter Agreement) coordinated the requirements of each legislative regime. This Agreement provided the foundation for the assessment process, as outlined in Table 2 .

Sources of information related to the empirical evidence discussed below included the Sable Gas project public registry, and semi-structured interviews with participants of the hearings. In terms of the public registry, information 
Table 2

Timelines of events in the panel review of the Sable Gas Panel Review (developed from CEA Agency 1997 and Sears 1997)

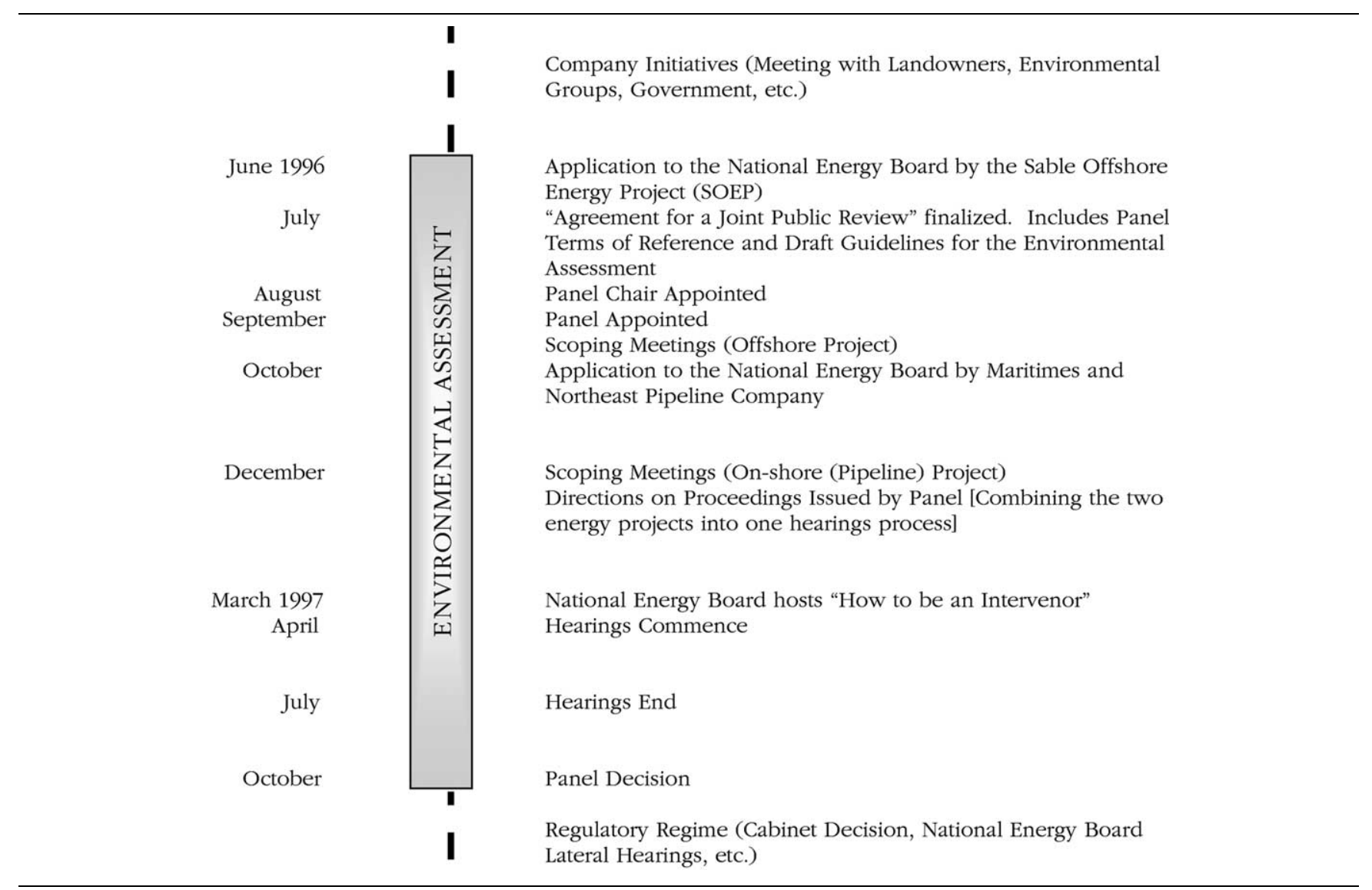

about the Sable Gas Panel Review was housed in various locales across the country. The Canadian Environmental Assessment Agency in Ottawa maintained the Panel Hearing Transcripts in the public registry. The National Energy Board Library in Calgary stored all the evidence submitted to the Panel during the hearings process, including the Environmental Impact Statement, documents related to the EA Process (i.e. minutes of the Scoping meetings), and intervenor evidence. Finally, individual members of the public and local institutions in the affected area maintained records of their activities related to the EA, including press releases, newsletters, workshop minutes, and survey results which were reviewed. In some cases, complete records of print media coverage, accessed at different library branches across Nova Scotia, New Brunswick, and Prince Edward Island complemented these private collections. All of these sources of project documentation and public input were considered during the study.

Following consideration of the literature and case documentation, informal interviews were conducted with 25 participants in November 2000. Participants from a cross-section of interest groups were approached to discuss the Sable Gas Panel Review. The research protocol drew on protocols developed for contemporary studies exploring the nature and function of learning through participation in the Canadian EA process (Sinclair and Diduck, 2001). Survey designs from earlier research were modified to reflect the purpose of this study. The primary purpose of the interview was to gain participants insights into the learning and education related dimensions of public involvement in a hearing situation. The main topics covered in the interview included issues such as the ways and means through which individuals participated in the hearing, the adequacy of the documentation, the panel process, and the learning that occurred and how it was facilitated.

Fig. 1 identifies the affiliation of participants in the study. The location of the interviews, selected by participants, predominately consisted of offices and coffee shops in Greater Halifax, Antigonish, Saint John and Fredericton. Meetings lasted between 30 min and $1 \mathrm{~h}$. With permission of participants, most of the interviews were recorded on audio-cassette, and transcribed, verbatim. This process was used to ensure a comprehensive record of meetings. Data were then coded by interview question.

A comprehensive analysis of the role of critical education in the Sable Gas project as defined by Shor's ten descriptors is not possible in the context of this paper (Fitzpatrick, 2001). Given this, ten operational definitions 
outlined in Table 1 that most clearly illustrate opportunities for critical education in an assessment that includes hearings are highlighted.

\section{Education and learning through a hearing}

\subsection{Participatory}

The first of the ideal conditions of learning considered was participatory. In terms of education, participatory education deals with the relationship between teacher and learner in developing a learning agenda. As applied to EA, this concept explores relationships between participants and the panel in determining the assessment agenda. Preparation and planning for an assessment is undertaken through scoping. Scoping is the process through which the panel establishes the boundaries of the project and determine what issues are relevant to the EA (CEAA, 1996). The results of the scoping form the basis of the EA guidelines. These guidelines describe, in detail, what must be considered by the proponent. The extent to which the EA participants contribute to the scope of the EA provides a foundation for discussing the participatory nature of the assessment process.

\subsubsection{Did the learners participate in developing the scope of the EA?}

The public was engaged in discussions surrounding the scope of the project through two media-attendance at local scoping meetings, and submission of written documentation. Members of the panel secretariat commented on these efforts:

"I worked to engage the public in series of scoping sessions. We selected the communities that we felt would be most affected by any adverse or positive outcomes, and we went to those communities. Prior to start of environmental review, we engaged public in dialogue and gave them opportunity to understand what the process would be (Alva)."

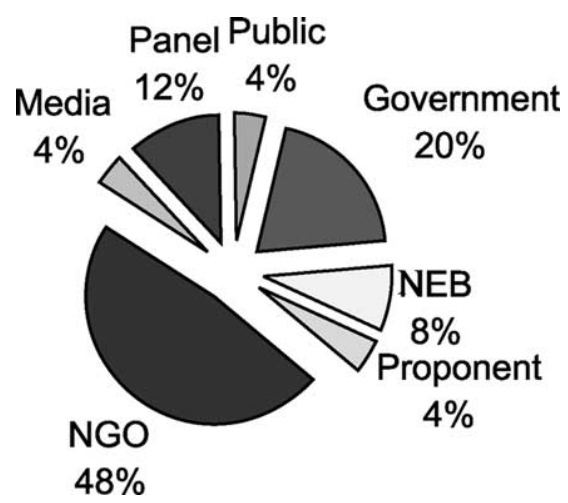

Fig. 1. Affiliation of participants in the study.
As noted in the scoping submissions and meeting minutes, participants represented a cross-section of interest groups. The general public, government, non-government organizations and industry submitted suggestions about what should be considered during the hearings.

The panel was asked to include a variety of issues related to

- the process (two projects under assessment, role of Traditional Knowledge, application of relevant regulations, nature of the hearings in terms of mitigating or preventing project);

- project alternatives (route, energy sources);

- economics (land valuation);

- social impacts (environmental illness, training and employment, quality of life, company history); and,

- the environment (monitoring programs, impacts to fish, potential for radioactive sludge, project decommissioning, stream crossings, greenhouse gas emissions, global warming).

While this process provided opportunities to dialogue among interested parties, the ultimate decision over the scope rested with the panel. To this end, the panel utilized many of the participants' suggestions.

"[W]e were given a set of issues at the outset; it came with the terms of reference. And the issues trebled (increased by a factor of three) as the result of the scoping sessions. The public broadened the whole issue package and redefined what we would be considering (Tracy)."

The strongest illustration of the utility of scoping relates to the overall hearings process. Whereas in the original terms of reference, the Panel was to evaluate the onshore and offshore components of the project independently, following the advice of Ecology Action Centre (EAC), the project was considered in it's entirety. EAC's argument was captured in the minutes of the scoping session:

"How can the Panel deal with questions on the viability of the whole project (i.e. the need for the project) if it is split into two separate applications? How will the interactions of the two projects be identified-if both halves of the project are marginal, how do you deal with it? (NEB, 1996)."

In response to EAC's submission, the panel considered the impacts of both the on-shore and offshore project in its entirety.

With three key exceptions, the issues listed above were ultimately considered during the hearings. Each of the three issues excluded, alternative energy sources, company history, and greenhouse gas emissions, had implications for social and individual behaviour which were deemed to 
go beyond the development of the Sable Gas Panel Review. This, however, is not to suggest that these issues should not, or cannot be considered within the context of an EA. The panel ruled, however, they were beyond the scope of the panel's jurisdiction.

\subsection{Situated}

The second descriptor of critical education pertains to the nature of the learning program in terms of the needs of participants. Is the material generated throughout the learning program, or EA, reflective of the language and content needs of participants? In terms of the assessment process, indicators of this criterion explore the relationship between participants and the assessment process.

\subsubsection{Was the EA documentation presented in plain language?}

When asked about the nature of the assessment documentation, participants expressed a range of opinions about the breadth of the material. Some felt that all issues were covered adequately in the assessment documentation, while others believed submissions by various groups reflected their biases.

This division of opinion is also reflected in participant understanding of the appropriateness of documentation discourse. Some public participants suggested the material was accessible to a cross-section of members of the public:

\footnotetext{
"As a matter of fact, in my presentation in Fredericton, I commented to the Panel, and to the proponents [about the documentation]. I thanked them for having a very user friendly document. Maybe having some knowledge of science and the environment helped me but I thought that anyone could have picked the material up, and without too much thinking, have understood what was going on (Meaghan)."
}

While some felt that documentation was user-friendly, and could be understood by members of the public, others found it more challenging:

\footnotetext{
"So we are hit hard with this massive documentation, which quite frankly was very, very difficult to get through. Although we did well on the environmental end, we were completely lost on the regulatory details, such as postage rates. The business end was completely out of our league (Laura)."
}

A third group suggested different ways to improve the general public's understanding of the proposal. These participants recognized the importance of and need for technical reporting in EA, but acknowledged the need to communicate these ideas with the broad public, including the media.
"So we felt both on the technical side-engineering, oceanography, petrochemical science, and also on a legal side, we usually had a lay person's knowledge on a lot of these things. We couldn't really assess the accuracy of the information. We felt that a lot of work had gone into the proponent's information-they put a lot of time and effort into it, but we couldn't start commenting about the accuracy of it. We thought that there might have been more plain language, both in the proponent's materials, and in the assessment process (George)."

This indicator illustrates the struggle to balance the varied needs of participants in the assessment process. Evidence presented during the hearings must reflect and respect the scientific and technical complexity of the proposal, however, this material must be presented in a way that can be used by members of the panel with expertise in other areas, and members of the public with varied educational backgrounds.

\subsubsection{Were the hearings conducted in a way to encourage participation?}

A strong theme that emerged from the interviews was that the mechanics of the hearings did not encourage participation by the public. According to participants, the decision to adopt a quasi-judicial approach to the hearings impacted the general public's willingness, and ability to participate in the hearings. On a superficial level, the formality of the process was noted by the attire of many of the public participants:

"And when we arrived that morning, I will never forget it. It was a big ballroom at the Lord Beaverbrook Hotel and we walked in and there were tables with table cloths, some seven or eight feet long, completely filled with people in suits and very expensive tailor made clothes who were there promoting and supporting the project, preparing to give evidence from their perspective, and sometimes questioning some of the environmental evidence. So here we are a group of ordinary community based citizens. We felt like a fish out of water (Laura)." "Well, just it's so formal. I think that is quite a turnoff to a lot of people - the staggering formality of the process... we had some experience coming into it, which is good. I could see some of the landowners, I am sure they felt just out of their league. You get in there with two hundred suits and you begin to question whether or not your point is a valid one and they can make you feel pretty soon that it isn't. Your questioning could be cut off-there were rules about what was relevant and what wasn't. It is a very daunting process for what you would consider the general public. It is so structured, so formal, and you almost feel like you should bring your own lawyer with you, just in case you slip up or say something really wrong (Andrew)." 
Accessibility is another important issue when considering opportunities for public engagement and education in an EA. The Sable Gas panel took steps to ensure that the hearings were open to all members of the public wishing to be involved. As per the panel terms of reference, informal hearings were held in Antigonish and Saint John prior to the commencement of the formal hearings. The informal sessions were open to all; people could walk off the street and provide their comments to the panel. Fig. 2 shows the affiliation of the 51 participants of the informal sessions.

To contribute to the formal hearings, however, participants were required to register as 'intervenors'. While this formality may have been a potential deterrent to participation, no one was denied intervenor status, regardless of the date of their application. When one applicant requested status mid-way through the hearings, the panel's decision to confer intervenor status was widely publicized. Fig. 3 shows the affiliation of the 125 registered intervenors.

Fig. 4 shows the affiliation of all participants of the Sable Gas Project hearings. As demonstrated in Figs. 2-4, representatives of industry dominated the hearings, accounting for more than $60 \%$ of all intervenors during the hearings. Participation by other groups was not as consistent. Members of the general public were more active in the two informal hearings, where they accounted for $29 \%$ of all participants. During the formal hearings, however, the general public consisted of only $2 \%$ of the intervenors; their participation was replaced by representatives of government, non-governmental organizations and Aboriginal government. The different representation levels of members of the general public between the informal and formal hearings support the assertions of participants that the formal nature of the quasi-judicial process may have deterred the involvement of the general public in the hearing.

A second factor that may have detracted from the Panel's efforts to ensure the hearings were accessible to the public involved the hearing schedule. The panel sat each weekday, between standard business hours (i.e. between 8:30 am and 5:00 pm). Accessibility, for those with conflicting schedules, due to work or school, was a frequent issue during the hearings.

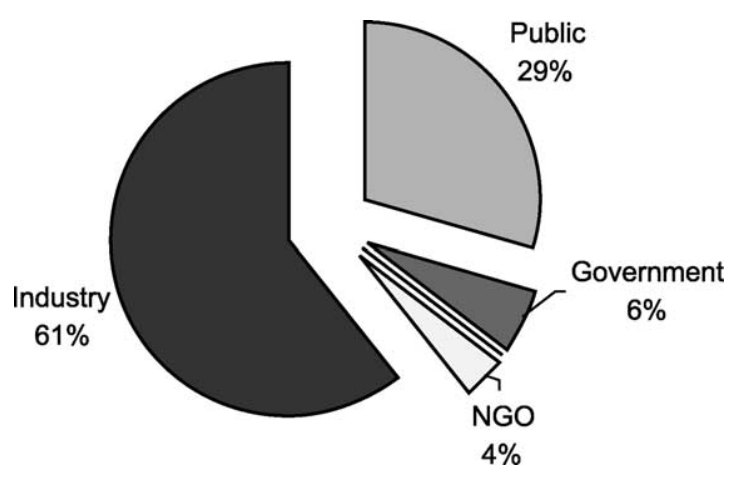

Fig. 2. Affiliation off participants in the informal sessions.

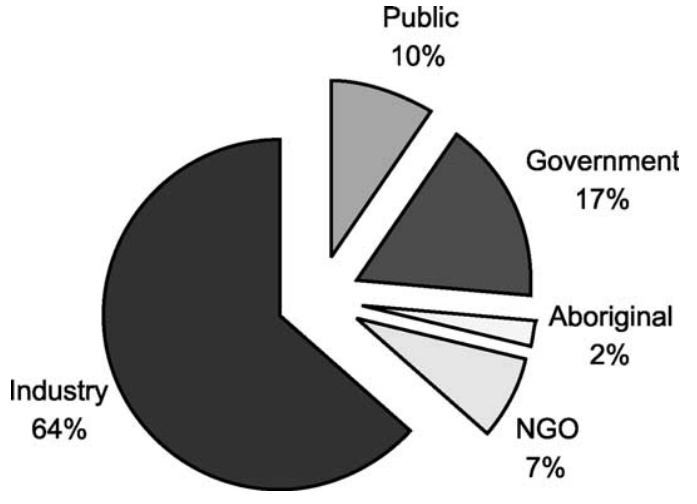

Fig. 4. Affiliation of all hearing participants.

"So, again, [the intervenors] are precluded from making their own presentation by the fact that this Hearing does not sit outside of normal business hours or normal school hours. (NEB 1997a: 10493)"

Although the panel worked to ensure the public could participate in the hearings (i.e. through activities including the provision of intervenor status to all interested parties, etc.), the panel schedule was an important barrier to broad-scale participation.

\subsection{Democratic}

Democracy relates to the fairness of the learning experience in terms of the development and implementation of the learning agenda. Given the varied positions of power of participants vis a vis financial and human resources, time, experience, and levels of education, the ability of participants to contribute to the learning agenda is contingent upon a redistribution of power relations. To this end, the primary indicator of democracy in terms of the panel review process looked at how the assessment process addresses power differentials of participants.

\subsubsection{Were steps taken to modify the hearings process to level power relations?}

Given the formal nature of the quasi-judicial process, the panel worked to level power relations between public

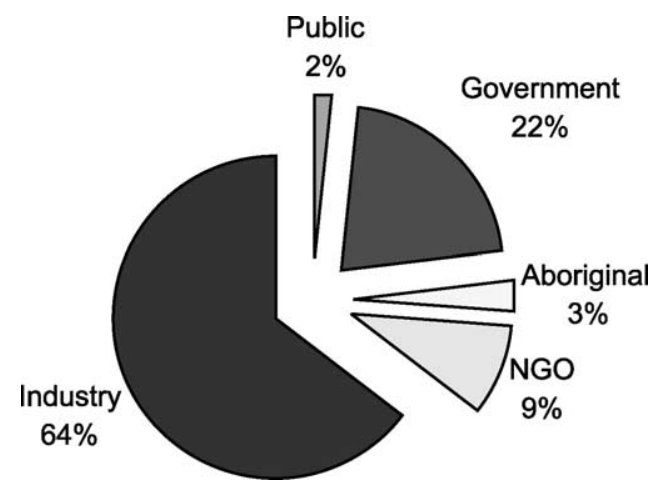

Fig. 3. Affiliation of registered intervenors. 
participants and representatives of national industries with significantly more resources. In addition to providing funding, as per the CEAA participant funding program, the panel presented a course for participants on how to be an intervenor, offered the services of the National Energy Board counsel to assist non-governmental organizations to develop motions, and provided leeway to participants with respect to standard rules of practice for judicial hearings. According to one member of the panel secretariat:

"[W]e tried to let everybody who wanted to participate in, and we tried to give everybody a chance to say what they had to say. We only cut them off in the end when it was clear that they were repeating themselves, that we weren't getting anywhere (Tracy)."

These steps, according to panel members, worked to 'level the playing field.' The ability of a person to represent their interest groups was not reliant on a law degree, but mastery of a particular topic.

"And that process can work for both. Sure the lawyers are slick... they do this for a living, but I saw lawyers humiliated. I saw lawyers embarrassed. I saw lawyers having to recant their information because somebody knew better than them. And the panel's not stupid, you know. I mean I am not a lawyer and I am not an environmentalist in the strictest sense, or I am not an oil company representative... but after a while you can tell baloney from non-baloney (Tracy)."

Participants, however, had a somewhat different perception of the process.

"We were in what has turned out to be quasi-legal proceedings at somewhat of a disadvantage, as neither of us has legal training or expertise, nor would our small Intervenor grant allow us to hire such services. A less legalistic proceeding would have contributed to a leveling of the playing field, and could have led to more open discussion (NEB, 1997a: 10643-10644)"

Many participants cited the need for legal representation and increased funding to effectively participate in the panel hearings, when challenging the gas industry and its legal counsel. Another member of the panel secretariat acknowledged this power differential:

"It certainly isn't equal. People who can pay an expensive lawyer-and people certainly made a lot of money-certainly do have a better kick at the can. On the other hand, some scientists who presented information were not lawyers and were incredibly effective. So it is a matter of learning the skills necessary to be involved. I think it was a positive process for a lot of people, but not everybody got what they wanted (Samantha)."
The judicial formality of the Sable Gas panel review served to restrict the ability of the panel members to foster equitable power levels among participants.

\subsection{Dialogic}

Programs of critical education encourage active discussion about topics in the learning agenda. Discussion among participants is an important component of critical education. In terms of an EA process that includes hearings, dialogue can be fostered both inside, and outside the hearings venue.

\subsubsection{Did the process encourage dialogue about potential solutions to outstanding issues?}

As the purpose of hearings is to explore potential project impacts and develop mitigation measures, where possible, this criterion explored the process leading up to the panel's recommendations. Were intervenors encouraged to discuss and develop potential solutions to outstanding issues? Responses addressing this question focused on the hearings format. Questions were raised concerning whether dialogue can develop in a quasi-judicial setting. Public participants were clear that they believed the quasi-judicial procedure, as implemented for the Sable Gas Panel Review, did not promote discussion and cooperative resolution of issues.

"Because the process is set up as winner and loser, there is not much discussion. What they are discussing is win or lose not ideas (Dana)."

"Dr Fournier at one point admonished one of the citizen presenters to remind them that the whole purpose of the hearings was to put information in front of the panel, so that the panel could make up its mind and fulfill it's mandate. And I have to say that is not my interpretation of what a public process is all about. The public has to be satisfied that their concerns have been raised, that their concerns have been taken seriously, that their concerns have been discussed, and that their concerns have been dealt with. If the public doesn't come away from a process reassured, then there is no buy-in to the decision (Patrick)."

While these statements do not suggest that participants believed issues were outstanding at the termination of the hearings, the process through which resolution was achieved was adversarial, as opposed to dialogical in nature. Representatives of the public felt that rather than fostering dialogue about potential solutions, the process fostered competition among participants.

\subsection{Desocialization}

Desocialization refers to how the learning program encouraged active participation. Encouraging the participant to take control works against the traditional structure of passive learning; the student moves from acting as 
a receptacle of external data to someone who works to decide what data is necessary. As discussed above, the literature on public involvement in EA encourages active participation (i.e. Diduck and Sinclair, 2002). To add depth to this examination, one operational definition provided a foundation for the investigation.

\subsubsection{Were steps taken to encourage inactive public to participate?}

Numerous activities directed at informing and engaging the public were undertaken by the panel, industry and non-governmental organizations. This criterion explored specifically how the secretariat worked to engage members of the public in the Sable Gas Panel Review. To this end, the panel secretariat office was relocated to Halifax. A public liaison officer from the affected community was appointed and directed to confer with interest groups and conduct media relations activities.

"I acted as a community liaison to stakeholder groups, and intervenors, and advised the panel and the public on the working of the joint panel. Like any communications officer, you have respond to who you report to, and act on their behalf. But in case of public review, you have responsibility to ensure that public was engaged in the process (Alva)."

Efforts to engage the public in the assessment were delegated to the panel secretariat, who made every effort to encourage participation in the assessment.

"I think [the secretariat staff] were endlessly accommodating to people who walked in off the street. [They provided people with] documents, and talked them through the material. That was their job. They did it extremely well. I never heard a complaint (Tracy)." "I am not sure how much more could have been done. The hearings were widely publicized. As I said, at some points the hearings were covered by six media organizations daily. And people from outside Nova Scotia were stunned by this. They said they had deals worth twice as much, and didn't receive a quarter of the coverage. So there was a lot of information (Brian)."

As illustrated by these responses, the panel secretariat was effective at providing information to members of the public, and making themselves accessible for public meetings. Despite these efforts, there was little representation by members of the public in the formal hearings, as noted above. Participants suggested a variety of factors that may have constrained public involvement in the hearings. These constraints, classified in terms of categories identified by Diduck and Sinclair (2002), include

- process deficiencies, including a lack of opportunity to dialogue about the project (Dana, Judy), and an inability to participate in the hearings due to timing (David);

- alienating dominant discourse, fostered through the formality of the hearings process (Laura, Patrick), and the proponent control of the public involvement (Laura);

- lack of institutional capacity available to participants, due to the extensive efforts required to adequately participate in the hearings (Maire);

- insufficient interest, due to the perception that the public was not directly affected by the development (Stephen);

- delegation of participation to others, particularly nongovernmental organizations who represented their interests (Scott);

- lack of understanding about technical issues (Dana), and the potential impacts of the project (David, Andrew, George); and,

- character traits, including apathy (Meaghan).

\subsection{Multicultural}

A multicultural curriculum acknowledges the cultural diversity of participants. In terms of the panel review process, operational definitions of this criterion explored efforts to attract participation by members of different cultural backgrounds. They also examined efforts to ensure the process balanced the needs of participants of different genders, races and classes.

\subsubsection{Did the process reflect the needs of participants (translation, location, process, etc.)?}

Logistically, several steps were taken to meet the diverse needs of participants in the Sable Gas hearing. First, the formal hearings were divided between two locations-New Brunswick and Nova Scotia, so residents of each province affected by the proposal could participate. Also, as New Brunswick is officially a bilingual province, French translation services were provided, as required. Additionally, in an attempt to respect the needs of people with environmental illness, the panel worked to encourage a scent-free environment.

The panel, however, did not accommodate all requests. One example involves a request for video-conferencing by Millwood Environmental Action Team.

"We had requested, on numerous occasions, for video conferencing. I requested videoconferencing so that we wouldn't have to make the long trek into Halifax, and so that students could present their evidence that way, but they refused to do so (David)."

Minimal effort to engage publics from different cultural backgrounds was cited as a barrier to participation by Aboriginal organizations. One member of the secretariat noted:

"Certain communities were problematic, primarily the Aboriginal Community. I think the issue stems primarily 
in the way the proponents considered them the same as any other community. They would just ship a bunch of documents to them assuming they have the resources and the will and the interest to disburse them, and have the organization and the infrastructure to become part of the process. And the Aboriginal Community felt very strongly that shipping of cartons of documents to an office is not sufficient (Samantha)."

Despite recognition of this deficiency in the proponent's application, it appears few steps were taken to encourage Aboriginal participation in the hearing or to help facilitate their understanding of the hearings documents. Beyond the allocation of participant funding, and the granting of intervenor status to three Aboriginal organizations who requested this right, no special efforts were undertaken to engage the Aboriginal community in the hearings process.

\subsection{Research-oriented}

This criterion refers to the nature of the activity. Does the learning agenda promote research by both the teacher and the student? In terms of the panel review process, the criterion was explored using two indicators, both related to opportunities for research resulting from the hearings.

\subsubsection{Did the panel encourage independent research by participants?}

As with all EAs that include hearings under CEAA, provisions were made under the participant funding program for stakeholders to apply for monies to finance research and administrative expenses. Funding dispersed in relation to the Sable Gas Panel Review totalled \$125,000. Money was distributed to the Conservation Council of New Brunswick; the Union of New Brunswick Indians; the Native Council of Nova Scotia; the Ecology Action Centre; the Maritime Pipeline Landowners Association; the Clean Nova Scotia Foundation; the Citizens Coalition for Clean Air; the Nova Scotia Salmon Association; and, the Allergy and Environmental Health Association.

“This funding contributed to each organization's ability to participate in the hearings. We did three things (with the monies allocated to our group through intervenor funding). One, we hired our own expert and produced a report." "Secondly, we produced evidence, official evidence that was put into the record. Thirdly, we were granted intervenor status presented (Laura)."

A survey of research undertaken for the Sable Gas Panel Review by participants is presented in Table 3 . The participant funding program provided resources to research key issues related to the EA, and participate in the hearings process.
"We hired a number of people to do studies, which I think had quite an impact on the process. We did a study on ice conditions in the North Atlantic that I think pressed them to come up with more detail. We did a study that had to do with alternative routes for the pipeline onshore, and that pushed them on the methodology of crossing waterways. So there were a variety of things that we did that were quite helpful to the process (Patrick)."

"Basically, I mean, thank god for intervenor funding because the little that we did have, we put to good use. We could have used a whole lot more, but if we didn't have that - there's no way [we could have participated] (Dana)."

This source of funding was appreciated by all recipients, however, concerns related to timing and level of funding were raised.

"For example, we found out that we got funding in December, and the hearings started in March, so there were only 4 months to work. And if you know anything about community development, four months is not a lot of time. And when you have eleven thousand dollars of intervenor funding to do a whole process in six month, versus millions of dollars going into EA assessments, by consultants for the company, obviously you can't do the same scope of work (Dana)."

Despite the extensive contribution of independent studies to understanding the environmental impacts of the Sable Gas project, panel participants felt that with additional time and money, more research could have been contributed to the Sable Gas hearings. Areas of interest identified by study participants included: the impact of the project on marine mammals (Patrick); the social impacts of the development at a community level (Dana); and, the public disassociation between the Sable Gas project and the government policy of sustainable development (Dana). Additional studies could have served to generate more discussion about the positive and negative impact of the proposal, and worked to level organizational capacity to effectively participate in the hearing.

\subsubsection{Did the material presented during the panel contribute to future research initiatives [outside the specific EA]?}

As with many EAs for large-scale projects, studies about project impacts continued following the panel's recommendation. As a condition of project approval, for example, the proponents were required to undertake numerous baseline and monitoring programs. These programs focused on valued ecosystems components, including waste discharges; water and sediment monitoring; data pertaining to wind and extreme events; underwater habitat 
Table 3

Survey of research submitted as evidence to the Sable Gas hearings

\begin{tabular}{|c|c|}
\hline Author & Scope \\
\hline Nova Scotia Salmon Association & $\begin{array}{l}\text { Freshwater Ecosystem, Watercourse Crossing; Riparian Zones; Erosion } \\
\text { and Sedimentation; Acid Drainage; Lateral Lines; Environmental } \\
\text { Inspectors' Environmental Protection Plan; and, Monitoring }\end{array}$ \\
\hline Seafood Producers Association of Nova Scotia & $\begin{array}{l}\text { Relationship between fisheries industry and petroleum development; } \\
\text { Observer Program; SOEP Fisheries Liaison Committee }\end{array}$ \\
\hline Allergy and Environmental Health Association, Nova Scotia & $\begin{array}{l}\text { Environmental Illness and chemical sensitivity; Indoor pollution and } \\
\text { natural gas use; cumulative effects; occupational risks; economic } \\
\text { implications; legal implications; alternative energy sources }\end{array}$ \\
\hline Maritime Pipeline Landowners Association & Easement and property rights, funding for efforts; compensation \\
\hline Conservation Council of New Brunswick & $\begin{array}{l}\text { Crossing of Salmon rivers; Recreational use of Easement; Burning of Wood } \\
\text { Waste; Vegetation Control; Avoidance of Wetlands; Moose; Old Growth } \\
\text { Beech Stand; Performance Bond; Acid Rock Area }\end{array}$ \\
\hline Ecology Action Centre & Corridor Selection Process \\
\hline Ecology Action Centre & $\begin{array}{l}\text { Economic Issues (Insufficient protection of Public Interest-time limit on } \\
\text { development rights, risks associated with Royalty Regime; Displacement of } \\
\text { Coal Industry; Net Benefit to Public Partner) }\end{array}$ \\
\hline Ecology Action Centre & Review of the Marine Environmental Impacts \\
\hline Ecology Action Centre & The Historical Record of SEA Ice in the Vicinity of Sable Island \\
\hline Earl Lockerby & $\begin{array}{l}\text { Natural Gas Other Energy Sources, Atmospheric Pollution and Global } \\
\text { Warming, Sustainable Development }\end{array}$ \\
\hline Saint John Citizens Coalition for Clean Air & Lateral Lines to Saint John, Air Pollution \\
\hline World Wildlife Fund & Protected Areas, Species of Concern \\
\hline Confederacy of Mainland Micmacs & $\begin{array}{l}\text { Archaeological Sites, Effects on Habitat of Fish, Wildlife and Traditional } \\
\text { Medicinal Plants; Effects on Land Claims; Employment and Economic } \\
\text { Opportunities }\end{array}$ \\
\hline Scotia Fundy Mobile Gear Fishermen's Ass. & Ecosystem, Economics, Discharges \\
\hline
\end{tabular}

data; and, geotechnical information related to the pipeline (Natural Resources Canada, 1997; NEB, 1997b).

In addition to project-specific monitoring programs, as a condition of approval by the Canada-Nova Scotia Offshore Petroleum Board, the proponents were required to contribute $\$ 5$ million over a 5 year period for research and development in Nova Scotia. Details regarding studies funded by this money, and the publics involvement in them were unavailable (Canadian Nova Scotia Offshore Petroleum Board, 1997).

\subsection{Activist}

Activist refers to the nature of the learning environment. According to Shor (1993: 34) the learning environment should be both 'active and interactive, thanks to problemposing, co-operative learning, and participatory formats.' Wherever possible, critical education should contribute to action learning through experience. As the EA process is explicitly designed to produce an action outcome the criterion for this descriptor focused on the learning environment.

\subsubsection{Did the hearings process encourage participants to engage in experiential learning?}

Experiential learning is the process of using a real-life experience as a method of learning about general principles that can be applied in future activities. In more colloquial terms, experiential education focuses on learning by doing-deconstructing specific activities for lessons which can be applied to life experience-rather than learning through reading about action-outcome.

The Sable Gas panel contributed to the experiential learning on two fronts. With the assistance of the participant funding program, a small group of (public) stakeholders became actively engaged in learning about the proposed pipeline.

"We actually went out and walked pipeline routes. We went to the communities where they were going to go. We would drive out and see if we agreed with what they said they were going to do (Andrew)."

Through a hands-on examination of areas under consideration, these participants suggested they had a greater understanding of the true impacts of project construction.

The second avenue for experiential learning affected all participants of the hearings. The quasi-judicial hearing serves as an experiential learning activity for all participants. A member of the panel secretariat explained this idea, expressed by many participants:

"You learn best by being in the process and doing it. I went to a formal class, and learned a lot, and it helped me in the formal process. But I will tell you my first week doing it. It was trial by fire. And it was scary, but it was 
a way to learn. We had a participant come in the beginning who was clearly embarrassed, uptight, frightened. It was intimidating. [The participant] watched what other people did, and he learned from it, and he got better and better. In the end, the criticisms of intimidating and adversarial came from people who only gave it a passing glance. But the ones who stuck with it and tried to learn the process did extremely well (Tracy)."

\section{Conclusion}

As shown by the events surrounding the Sable Gas panel review, participants of an EA that includes hearings have opportunities to engage in critical education. The results also highlight the contribution of critical education to effective and fair public participation processes. As well, the attributes of the participation process in the Sable Gas case that promoted critical education strengthen arguments for the need to improve participation activities in many areas already identified in the literature, as discussed below.

The activity that promoted critical education most strongly involved the provision of intervenor funding. As with all panels conducted under CEAA, money was provided to various groups to encourage participation and independent research related to the impacts of the project. This research served as a foundation for the crossexamination of expert witnesses who presented the company's impact statement at the hearings. Both the participants who received funding and the panel recognised the value of the research in terms of a broader understanding of the potential project impacts. These findings support evidence in the literature suggesting the need to correct a serious shortcoming of public participation in terms of the lack of resources available to community members to participate effectively and the absences of provisions for participant funding to address this problem (Canadian Environmental Network, 1988; Friders, et al., 1992; Gibson, 1993; Smith, 1993; Wood, 1995).

The second category of activities that fostered a more critical experience by participants involved the opportunity to formally engage in the dialogue about the project. Fifty-six days of hearings served as the primary forum through which participants could debate the potential impacts of the Sable Gas project and could learn the perspectives of others on the project. The provision of legal guidance for all participants, and a course on how to be an intervenor were sound attempts to ensure that all participants could effectively participate in the hearing format. In this regard the Sable Gas case began to address the concern established in the literature about the scarcity of opportunities to engage in discussion and have arguments evaluated in a systematic fashion (Owen, 1998; CEAA, 1999; Petts, 1999). As discussed below, 'dialogue' was still a shortcoming of the Sable Gas case.
Strong public involvement activities rely on sound information exchange. One of the strengths of the Sable Gas case was that participants had access to all material related to the assessment, through the public registry, or the formal evidence record maintained by the National Energy Board, on which to base their research and interventions. The literature establishes that full access to information has been problematic, indicating that the extent of information accessibility that occurred in the Sable Gas Panel Review needs to be more widespread (Praxis, 1988; Frideres et al., 1992; Canter, 1996; Mitchell, 1997; CEAA, 1999).

Despite the efforts to make the hearings more amiable to participants, one of the strongest criticisms of the EA, expressed by representatives of the public, related to the quasi-judicial process of the hearings. The Sable Gas Panel Review hearings process served to: (1) discourage participation by the general public; (2) affect the ability of the panel to level power relations among participants; (3) foster an environment where not all evidence was given equal consideration in the assessment decision; and, (4) most importantly in terms of learning, decrease opportunity for open dialogue about potential solutions to the project issues raised. These criticisms must be weighed against the requirement of the hearings to meet the needs of National Energy Board legislation, and the strength of the tool of cross-examination for measuring the validity of a statement. The criticisms do, however, support evidence in the literature of the need to further balance the relationship between the proponent, decision makers and the public in EA public participation activities (Kartez and Bowman, 1993; Regnier and Penna, 1996; Petts, 1999; Sinclair and Diduck, 2001).

A second criticism also focused on the hearing format. Given the submission of evidence and cross-examination, opportunities for participants to engage in dialogue about issues were restricted. Issues were addressed through questions and answers, rather than discussion. As one hearing's panellist noted, the hearing was not about discussing solutions to problems, but presenting evidence for scrutiny by the panel. This lack of engagement in dialogue seriously limits the learning potential for all parties involved in the hearing.

Thirdly, the results support the findings of 'Sinclair and Diduck (2001) and Petts (1999) of the need to provide support to participants in helping them wade through the proponents EA documentation, laden with technical language. As the results indicate, sending a box of EA documentation to most communities, and particularly First Nation, is of little benefit without technical support.

Finally, a serious inhibitor of the critical educational experience related to the time commitment required by participants. With over 56 days of hearings, participation in this review could not be undertaken by members of the public who were not paid to participate. This limited people's ability to learn from what was presented at the hearings and to informally discuss those positions. 
While it is important to acknowledge that the panel did not set out to engage participants in a 'critical educational' experience, each of the operational definitions of critical education were addressed to varying degrees, through activities undertaken by the panel secretariat. These efforts can be ascribed to a variety of motivations, including a desire to ensure the project was subject to a comprehensive evaluation of the environmental impacts before construction; a need to meet the legal requirements of five assessment Acts; an attempt to level power relations and resources among participants of the process to allow for a more equitable participation; and a desire to assist nongovernmental organizations in their efforts to effectively contribute to the hearings process.

The hearings process served as a chance for participants to critically dialogue about the project. Opportunities for critical education improved the implementation of participatory democracy in EA, public support of the assessment process and final panel decision making-all important criteria to any evaluation of fair and effective participation. Considering public participation in the context of critical education also provides further evidence of the need to modify current public involvement practices.

\section{Acknowledgements}

The authors wish to acknowledge the financial support of the Social Sciences and Humanities Research Council of Canada. The authors also wish to thank the anonymous reviewers whose comments improved the paper.

\section{References}

Alexander, D., 1999. Planning as learning: sustainability and the education of citizen activists. Environments 27 (2), 79-87.

Canada Nova Scotia Offshore Petroleum Board, 1997. Canada Nova Scotia Offshore Petroleum Board Responds to the Report of the Joint Public Panel Review, Canada Nova Scotia Offshore Petroleum Board, Halifax, NS.

Canadian Environmental Network, 1988. A Federal Environmental Assessment Process: The Core Elements, Canadian Environmental Network, Environmental Planning and Assessment Caucus, Ottawa.

Canter, L.W., 1996. Environmental Impact Assessment, second ed, McGraw-Hill, New York, Chapter 16.

C.E.A. Agency, 1996. Responsible Authorities Guide to the Canadian Environmental Assessment Act, Canadian Environmental Assessment Agency, Ottawa, Canada.

C.E.A. Agency, 1997. Joint Public Review Panel Report (The Sable Gas Project), Canadian Environmental Assessment Agency, Ottawa, Canada.

C.E.A. Agency, 1999. Review of the Canadian Environmental Assessment Act: A Discussion Paper for Public Consultation, Minister of the Environment, Ottawa, Canada.

Chapin, H., Deneau, D., 1978. Access and the Policy-Making Process, Ottawa Council on Social Development, Ottawa, Canada.
Clover, D.E., 1995. Theoretical foundations and practice of critical environmental adult education in Canada. Convergence 28 (4), 44.

Clover, D.E., 1996. Developing international environmental adult education: the challenge, theory and practice. In: Filho, W.L., Murphy, Z., O'Loan, K. (Eds.), A Sourcebook for Environmental Education: A Practical Review of the Belgrade Charter, Parthenon, London, pp. $92-111$.

Diduck, A., 1999. Critical education in resource and environmental management: Learning and empowerment for a sustainable future. Journal of Environmental Management 57, 85-97.

Diduck, A., 2001. Learning through public involvement in environmental assessment: a transformative perspective, $\mathrm{PhD}$, University of Waterloo; Waterloo.

Diduck, A., Sinclair, A.J., 1997a. The concept of critical environmental assessment education. The Canadian Geographer 41 (3), 294-307.

Diduck, A., Sinclair, A.J., 1997b. Testing the Concept of Critical Environmental Assessment (EA) Education. In: Sinclair, A.J., (Ed.), Canadian Environmental Assessment in Transition, Department of Geography, Waterloo, pp. 78-124.

Diduck, A., Sinclair, A.J., 2002. Public involvement in environmental assessment: the case of nonparticipant. Environmental Management 29, $578-588$.

Fitzpatrick, P.J., 2001. The role of critical assessment in a panel that includes hearings, Masters, The University of Manitoba; Winnipeg, MB.

Forester, J., 1989. Planning in the Face of Power, University of California Press, Berkley.

Fox, D., 1979. Public Participation in Administrative Proceedings, Law Reform Commission of Canada, Ottawa

Freire, P., 1973. Pedagogy of the Oppressed, The Seabury Press, New York.

Frideres, J.S., Fleishing, U., Goldenberg, S., DiSanto, J., 1992. Community participation: natural resource development in rural Alberta. In: Frideres, J.S., (Ed.), A world of communities: participatory research perspectives, Captus University Publications, Toronto, pp. 191-203.

Gelhorn, E., 1971. Public participation in administrative proceedings. Yale Law Journal 81, 359-387.

Gibson, R.B., 1993. Environmental assessment design: lessons from the Canadian experience. The Environmental Professional 15, 12-24.

Kartez, J.D., Bowman, P., 1993. Quick deals and raw deals: a perspective on abuses of public ADR principles in Texas resource conflicts. Environmental Impact Assessment Review 13, 319-330.

Merriam, S.B., Caffarella, R.S., 1999. Learning in Adulthood. A Comprehensive Guide, Jossey-Bass, San Francisco.

Mitchell, B., 1997. Resource and Environmental Management, Longman, Waterloo, Ont.

Natural Resources Canada, 1997. Government of Canada Responds to the Report of the Joint Public Panel Review, Natural Resources Canada, Ottawa, Canada.

NEB, 1996. A-1-11 Scoping Minutes, National Energy Board, Halifax.

NEB, 1997a. Energy Board Responds to the Report of the Joint Public Panel Review, NEB, Calgary, AB.

NEB, 1997b. Gas Panel Review Transcripts, National Energy Board, Halifax.

Orr, D., 1994. Earth in Mind: On Education and the Human Prospect, Island Press, Washington, DC.

Owen, S., 1998. Land use planning in the nineties: core lessons. Environments 25 (2/3), 14-26.

Palerm, J.R., 2000. An empirical-theoretical analysis framework for public participation in environmental impact assessment. Journal of Environmental Planning and Management 43 (5), 581-600.

Parenteau, R., 1988. Public Participation in Environmental DecisionMaking, Federal Environmental Assessment Review Office, Ottawa, Canada.

Pearce, D.W., Edwards, L., Beuret, G., 1979. Decision-Making for Enery Futures: A Case of the Windscale Inquiry, Macmillan, London, in association with SSRC. 
Petts, J., 1999. Public participation and environmental impact assessment. In: Petts, J., (Ed.), Handbook of Environmental Impact Assessment, Blackwell Science, Oxford, pp. 145-177.

Praxis, 1988. Public Involvement: Planning and Implementing Public Involvement Programs, Praxis, Calgary.

Regnier, R., Penna, P., 1996. The limits of empowerment in anti-nuclear advocacy: a case study of adult education for technological literacy. The Canadian Journal of Adult Education 10 (2), 35-57.

Sears, J.T., 1997. Report of the Commissioner on the Sable Offshore Energy Project, Nova Scotia Offshore Petroleum Board, Halifax, NS.

Shepard, A., Bowler, C., 1997. Beyond the requirements: improving public participation. Journal of Environmental Planning and Management 40 (6), 725 .

Shor, I., 1993. Education is Politics: Paulo Freire's Critical Pedagogy. In: McLaren, P., Leonard, P. (Eds.), Paulo Freire: A Critical Encounter, Routledge, New York, pp. 25-35.

Sinclair, A.J., Diduck, A., 1995. Public education: an undervalued component of the environmental assessment public involvement process. Environmental Impact Assessment Review 15, 219-240.

Sinclair, A.J., Diduck, A.P., 2001. Public involvement in E.A. in Canada: a transformative learning perspective. Environmental Impact Assessment Review 21, 113-136.
Smith, L.G., 1993. Impact Assessment and Sustainable Resource Management, Wiley, New York.

Susskind, L., Cruikshank, J., 1987. Breaking the Impasse: Consensual Approaches to Resolving Public Disputes, Basic Books, New York.

Tauxe, C.S., 1995. Marginalizing public participation in local planning: an ethnographic account. Journal of American Planning Association 61 (4), 471-481.

Usang, E.A., 1992. Strategies for green literacy. Convergence 25 (2), 46.

Usher, P.J., 2000. Traditional ecological knowledge in environmental assessment and management. Arctic 53 (2), 183-193.

Webler, T., 1995. Right discourse in citizen participation: an evaluative yardstick. In: Renn, O., Webler, T., Wiedemann, P. (Eds.), Fairness and Competence in Citizen Participation: Evaluating Models for Environmental Discourse, Kluwer, Dordrecht, pp. 35-86.

Webler, T., Kastenholz, H., Renn, O., 1995. Public participation in impact assessment: a social learning perspective. Environmental Impact Assessment Review 15, 443-463.

Wood, C.W., 1995. Environmental Impact Assessment: A Comparative Review, Longman, London.

Zimmerman, J.F., 1986. Participatory Democracy: Populism Revived, Praeger, New York. 